\title{
Flame Structure and Ignition Limit of Partially Premixed Cool Flames in a Counterflow Burner
}

\author{
Christopher B. Reuter, Sang Hee Won, Yiguang Ju \\ Department of Mechanical and Aerospace Engineering \\ Princeton University, New Jersey 08544, USA
}

\begin{abstract}
Due to their natural coupling of low-temperature chemistry and transport, cool flames are a valuable platform for drawing fundamental understandings of complicated phenomena relevant to real engines. In this study, self-sustaining partially premixed cool flames of dimethyl ether are investigated in detail through the use of an ozone-assisted counterflow burner. A double cool flame with distinct diffusion flame and premixed flames sides is visibly observed at increased fuel loading and equivalence ratio. The examination of double cool flames and double hot flames through planar-laser induced fluorescence measurements reveals the stark differences in the role of $\mathrm{CH}_{2} \mathrm{O}$ in each. The results show that while $\mathrm{CH}_{2} \mathrm{O}$ is one of the main product species of the cool flame via low-temperature chemistry, for the hot flame it is only a short-lived intermediate produced in the preheat zone. Comparisons of experimental results with numerical calculations based upon detailed chemical kinetic models show fair agreement on the double cool flame structure but a noticeable discrepancy in the prediction of the second-stage ignition limit, which triggers the transition from cool flames to hot flames. The critical strain rate for second-stage ignition is shown to be much more sensitive to fuel addition on the premixed side of the double flame than on the diffusion side. A mechanism for second-stage ignition in partially premixed cool flames is proposed based upon numerical modeling and experimental observations: $\mathrm{H}_{2} \mathrm{O}_{2}$ is primarily formed in the premixed cool flame, diffuses toward the stagnation plane, and then finally decomposes into $\mathrm{OH}$ radicals upon approaching the cool diffusion flame.
\end{abstract}


Keywords: Cool flame; Partially premixed flame; Low-temperature chemistry; Second-stage ignition; Ozone 


\section{Introduction}

Cool flames offer an intriguing platform for fundamental combustion studies, with applications including knocking in spark-ignition engines [1], ignition timing in advanced compression-ignition engines [2], and even fire safety in space [3]. These flames, discovered centuries ago [4, 5], are governed not by the small-molecule high-temperature chemistry that drives their hot flame counterparts but by a less understood series of low-temperature reactions involving large fuel molecules. Many studies over the last few decades have advanced the knowledge of cool flames through the use of stirred reactors [6, 7], heated plates [8], and heated reactors [9, 10]. These investigations have provided insights into the temperature range of cool flames, their typical products and intermediates, and the relevant lowtemperature chemical kinetics.

Despite these advances, most of the previous cool flame studies involved flames that were transient, oscillatory, or affected by complicated flame-wall interactions. A more detailed experimental study of cool flame structure, dynamics, and chemistry necessitates a stable and self-sustaining flame with unambiguous boundary conditions. Microgravity experiments $[3,11,12]$ have been able to produce selfsustaining cool flames lasting several seconds, but experiments of this type are often limited in scale, by transient processes, and by cost concerns.

Recently, however, insights from plasma-assisted combustion [13] have led to the development of an experimental platform for establishing self-sustaining cool flames in a counterflow burner [14]. In this setup, a dielectric barrier discharge from an ozone generator is used to create an oxidizer stream consisting of both $\mathrm{O}_{2}$ and $\mathrm{O}_{3}$ molecules. This method enhances the low-temperature chemistry (through ozone decomposition into $\mathrm{O}$ radicals) sufficiently to produce stable cool flames but at the same time maintains well-defined boundary conditions. The ozone-assisted counterflow burner setup has been successful in creating self-sustaining cool flames in both diffusion [14] and premixed [15] configurations. 
While investigations of pure diffusion and premixed flames are unequivocally valuable in themselves, a great number of situations also involve partially premixed flames. Unwanted fires can often begin with the transport of partially premixed fuel and oxidizer to a flame [16]. It is also known that partially premixed flames with strong low-temperature chemistry can stabilize in the stratified mixing layer, forming poly-brachial structures $[17,18]$. Perhaps most relevant to cool flames, advanced compression-ignition techniques such as partial fuel stratification (PFS) [19] and reactivity controlled compression ignition (RCCI) [20] rely on a two-stage ignition process that begins with the injection of a fuel-rich stream into a well-mixed fuel-air charge. The ignition timing for these compression-ignition processes is strongly affected by the cool flame, since higher heat release in the cool flame will cause second-stage ignition to occur more quickly $[2,21]$. Therefore, the study of partially premixed cool flames can provide new understandings of the interactions between transport phenomena and low-temperature chemistry occurring in these engines that cannot be gathered from simple zero-dimensional kinetic experiments such as flow reactors and jet-stirred reactors.

With these points in mind, the objective of this study is to examine self-sustaining partially premixed cool flames using the aforementioned ozone-assisted counterflow burner setup. First, the methods for establishing a stable double cool flame (consisting of a diffusion flame side and a premixed flame side) are discussed. The flame structure is then examined using $\mathrm{CH}_{2} \mathrm{O}$ planar laser-induced fluorescence to make comparisons between the double cool flame and a conventional double hot flame. Finally, the factors affecting second-stage ignition from partially premixed cool flames to hot flames, such as important species and reaction pathways, are explored.

\section{Experiment}


The platform for this experiment consists of a heated counterflow burner identical to the one in several previous studies [14, 15, 22-25], coupled with an ozone generator. A simplified schematic of the burner can be seen in Fig. 1. The oxidizer, which initially consists of pure (>99.9\%) oxygen, is first directed through the ozone generator (Ozone Solutions, TG-20) to produce an $\mathrm{O}_{2} / \mathrm{O}_{3}$ stream. The oxidizer stream is then mixed with dimethyl ether (DME), and the premixture (which is stable at $300 \mathrm{~K}$ ) is directed to the bottom burner. DME is chosen as the fuel due to its strong low-temperature chemistry, low boiling point (heating the premixture would destabilize the ozone), and relatively well-studied chemical kinetic models [26-28]. The ozone concentration (defined here as the mole fraction of ozone in the oxidizer stream) is measured by absorption spectroscopy [29] and can be correlated to the initial oxygen flow rate, as described in [14]. For all measurements in this study, the oxygen flow rate is held constant, resulting in an ozone concentration of $3.5 \%$. The upper burner expels a DME/ $\mathrm{N}_{2}$ mixture, which is heated to $550 \mathrm{~K}$ in order to decompose the ozone supplied by the bottom burner. Both burners have nozzle diameters of $13 \mathrm{~mm}$, and the separation distance between the two is set to $2.25 \mathrm{~cm}$. The strain rate $(a)$ in this study is defined as the density-weighted gradient of the axial flow velocities [22-24, 30]. For the partially premixed flames $\left(a=73 \mathrm{~s}^{-1}\right)$, the flow velocity from the lower burner is $41 \mathrm{~cm} / \mathrm{s}$ for all equivalence ratios used, while the upper burner velocity varies from $61 \mathrm{~cm} / \mathrm{s}\left(X_{F}=0\right)$ to $50 \mathrm{~cm} / \mathrm{s}\left(X_{F}=0.44\right)$. Video recording of cool flame initiation and second-stage ignition is performed at 125 frames per second by a high-speed camera (Photron, Fastcam SA-X).

For $\mathrm{CH}_{2} \mathrm{O}$ planar laser-induced fluorescence (PLIF) [31], the third harmonic (355 nm) of an Nd:YAG laser (Quantel, Q-smart 850) is used to produce a 200- $\mu$ m-thick vertical sheet, which is positioned along the burner centerline. A laser energy of $200 \mathrm{~mJ} /$ pulse is sufficient to excite the $\mathrm{CH}_{2} \mathrm{O}$ in the flow. An ICCD camera (Princeton Instruments, PI-MAX 4) captures the $\mathrm{CH}_{2} \mathrm{O}$ fluorescence with the aid of two band filters which pass frequencies between 400 and $450 \mathrm{~nm}$. 
The numerical modeling in this study employs the AramcoMech 1.3 [27] kinetic model for DME chemistry. The ozone submodel consists of the reactions proposed by Ombrello et al. [29] with the update from [32]. Calculations of species profiles are performed by the OPPDIF [33] module of the CHEMKIN package with a plug flow assumption. Calculations of ignition-to-extinction S-curves use a modified PREMIX code [34] with an improved arc-length continuation method [35] and a potential flow assumption.

\section{Results and discussion}

\subsection{Establishment of steady cool flames}

Depending on the mixture conditions (equivalence ratio, strain rate, etc.), stable ozone-assisted cool flames may be established in several different ways. For this study, three different methods were successfully tested: (1) auto-ignition, (2) laser-induced ignition, and (3) extinction transition from a hot flame. The circumstances necessary for each are described below.

Auto-ignition is the most straightforward way to establish a stable cool flame in that the flame will simply appear after a few seconds under favorable conditions. Low strain rates $\left(a<60 \mathrm{~s}^{-1}\right)$ are typically required so that the low-temperature induction chemistry time scale does not exceed the flow time scale. Auto-ignition occurs more readily for higher equivalence ratios, fuel loading, and ozone concentrations, but excessive amounts of fuel addition can result in two-stage ignition and the establishment of a hot flame.

For laser-induced ignition of a cool flame, the fourth harmonic $(266 \mathrm{~nm})$ of an Nd:YAG laser (Quantel, Q-smart 850) is used. A cylindrical plano-convex lens (focal length of $500 \mathrm{~mm}$ ) is used to focus the laser beam at the centerline of the burner approximately midway between the two nozzles. The number of shots necessary to ignite the cool flame is somewhat dependent on the strain rate and other flow 
conditions. For a few optimal cases (particularly at low strain rates), a single shot at $100 \mathrm{~mJ}$ is able to induce a cool flame. Most of the successful cases require 3-4 shots. The laser pulse provides a kinetic enhancement to the mixture rather than a thermal one, as ozone molecules are photodissociated at this wavelength into $\mathrm{O}_{2}$ molecules and (more importantly) $\mathrm{O}$ radicals. This effectively introduces $\mathrm{O}$ radicals into the premixture at an earlier time, since in the usual configuration ozone does not decompose until it reaches the temperature gradient near the stagnation plane.

At very lean $(\phi<0.09)$ equivalence ratios and very low (approximately $\left.X_{F}<0.04\right)$ fuel loading, it is possible to have a cool flame extinction strain rate that exceeds the hot flame extinction strain rate due to the reduced temperature sensitivity of cool flames $[15,36]$. An instance of this method is shown in Fig. 2, where a stable premixed hot flame at $\phi=0.102(t=0 \mathrm{~s})$ is gradually reduced to approximately $\phi=0.09$. As $\phi$ drops, the hot flame speed decreases until it is eventually surpassed by the cool flame speed, and a leading cool flame appears upstream of the hot flame. When hot flame extinction finally occurs $(t=28.15$ s), it does not extinguish into an unburning mixture, but the premixed cool flame remains. The cool flame will then remain stable so long as it remains between the cool flame extinction limit and the second-stage ignition limit [15]. A full video of this sequence is included in the supplemental material.

\subsection{Observations of partially premixed cool flames}

One of the main objectives of this experiment is the establishment of a partially premixed cool flame with a double cool flame structure, specifically, a flame with distinct cool diffusion flame and premixed cool flame sides. A direct photo of such a flame can be seen in Fig. 3a. High fuel loading in the upper burner, (in this case, $X_{F}=0.44$ ) is required to enhance the weak chemiluminescence from the cool diffusion flame. Additionally, the premixed cool flame must be allowed to propagate far enough upstream (toward the bottom burner) so that the two flames are separated. This is controlled by the strain 
rate $\left(a=73 \mathrm{~s}^{-1}\right)$, equivalence ratio $(\phi=0.11)$, and ozone concentration in the oxidizer stream $(3.5 \%)$. However, these factors must be balanced appropriately so that the second-stage ignition limit is not reached.

A double hot flame at the same mixture conditions as the double cool flame in Fig. 3a is shown in Fig. 3b. Note that the cool flame photo was taken at a shutter speed of $1 \mathrm{~s}$, while the hot flame photo was at a shutter speed of $1 / 100 \mathrm{~s}$. In comparing the two flames, the hot flame is noticeably brighter, particularly on the diffusion flame side. It is interesting that while the double hot flame exhibits much more chemiluminescence in its diffusion flame, for the double cool flame the premixed side is actually brighter.

In order to visualize the cool flame structure, $\mathrm{CH}_{2} \mathrm{O}$ planar laser-induced fluorescence (PLIF) measurements were performed. Figures $4 \mathrm{a}$ and $4 \mathrm{~b}$ show the raw PLIF images of a double cool flame and double hot flame at the same conditions as the direct photos in Figs. 3a and 3b. Although the hot flame is much brighter in the direct photos, the cool flame exhibits a peak centerline $\mathrm{CH}_{2} \mathrm{O}$ PLIF signal nearly four times stronger. In the cool flame, $\mathrm{CH}_{2} \mathrm{O}$ is one of the main products and is formed primarily through lowtemperature reactions such as QOOH decomposition $\left(\mathrm{CH}_{2} \mathrm{OCH}_{2} \mathrm{O}_{2} \mathrm{H}=\mathrm{OH}+2 \mathrm{CH}_{2} \mathrm{O}\right)$. This results in a single peak in the cool flame PLIF signal, as $\mathrm{CH}_{2} \mathrm{O}$ formed in both sides of the double cool flame is not fully consumed in the burned gas but diffuses towards the stagnation plane. However, in the hot flame, $\mathrm{CH}_{2} \mathrm{O}$ is only an intermediate species produced mostly through $\mathrm{R}$ radical decomposition $\left(\mathrm{CH}_{3} \mathrm{OCH}_{2}=\right.$ $\mathrm{CH}_{2} \mathrm{O}+\mathrm{CH}_{3}$ ) in the preheat zones and is quickly oxidized to $\mathrm{HCO}$ once it reaches the main hightemperature reaction zones. For this reason, the hot flame PLIF signal peaks twice-slightly before the reaction zones of the diffusion and premixed flames.

The centerline $\mathrm{CH}_{2} \mathrm{O}$ PLIF signal can be compared to numerical results from the AramcoMech 1.3 kinetic model [27] using a plug flow assumption. The comparison at $X_{F}=0.44$ and $\phi=0.11$ is shown in Fig. 5. At these conditions, the model matches the location of the peak $\mathrm{CH}_{2} \mathrm{O}$ in the hot diffusion flame 
decently, erring only by $0.7 \mathrm{~mm}$. It does underestimate the thickness of the $\mathrm{CH}_{2} \mathrm{O}$ profile in the hot diffusion flame, however, as its full width at half maximum is only $50 \%$ of the PLIF signal's. The 4.7 $\mathrm{mm}$ misprediction of the premixed hot flame location can primarily be attributed to improper boundary conditions caused by interactions between the hot flame and bottom burner exit.

The numerical model was unable to replicate the double cool flame at the conditions of Fig. 5 due to a crossing of the predicted second-stage ignition limit. In other words, a higher strain rate or lower amount of fuel was needed to provide a condition where the model and experiment could be compared. Such an instance is shown in Fig. 6, where the fuel loading has been decreased to $X_{F}=0.35$ and the equivalence ratio to $\phi=0.08$. While in the visible spectrum there is no longer a distinct double cool flame due to the decreased separation distance between the cool diffusion flame and premixed cool flame, the $\mathrm{CH}_{2} \mathrm{O}$ PLIF signal is still strong. Like the higher fuel loading, richer case (Fig. 4), the $\mathrm{CH}_{2} \mathrm{O}$ peak is located on the diffusion flame side, which the model predicts within $0.8 \mathrm{~mm}$. The full width at half maximum is also within $20 \%$ of the experiment. In the vicinity of the premixed cool flame, there is a bulge in the $\mathrm{CH}_{2} \mathrm{O}$ profile due to a second production source of $\mathrm{CH}_{2} \mathrm{O}$. Both the numerical calculations and the PLIF signal show a monotonic decrease in $\mathrm{CH}_{2} \mathrm{O}$ across the premixed cool flame front, however.

\subsection{Second-stage ignition of partially premixed cool flames}

As was briefly mentioned in the previous section, numerical modeling of the conditions for visible double cool flames (that is, at increased $X_{F}$ and $\phi$ ) often failed due to the overprediction of the secondstage ignition (SSI) limit, at which the cool flame transfers into a hot flame. Figure 7 depicts a regime diagram for partially premixed cool flames, including stable flame conditions from the experiment, the experimentally determined SSI limit, and a small survey of numerically predicted SSI limits. The models tested include the Zhao model from Princeton [26], the AramcoMech 1.3 model from NUI Galway [27], 
the reduced DME model from UC-San Diego [28]. The numerical models cannot reproduce the experimental points which lie to the right of their predicted SSI limits, which includes several of the stable partially premixed flames. Due to the importance of SSI as a part of the two-stage ignition process, it is worthwhile to investigate further the factors which are responsible for this phenomenon.

At SSI, the principal pathways of heat release and radical production in the flame shift from lowtemperature chemistry to intermediate-temperature chemistry, and as a result the cool flame transitions into a conventional hot flame. This can be understood as a turning point in the classic S-curve of flame temperature versus strain rate. Below the second-stage ignition strain rate $\left(a_{S S I}\right)$, a stable cool flame cannot be formed for a given mixture. For the partially premixed cool flames in this study, $a_{S S I}$ can be modified by changes in either the upper burner $\left(\mathrm{DME} / \mathrm{N}_{2}\right)$ fuel loading or the lower burner $\left(\mathrm{DME} / \mathrm{O}_{2} / \mathrm{O}_{3}\right)$ equivalence ratio.

Figure 8 shows the S-curves for several partially premixed cool flames near the SSI turning point. It can be seen in Fig. 8a that $a_{S S I}$ is only weakly sensitive to fuel loading on the diffusion flame side. An increase from $X_{F}=0.25$ to $X_{F}=0.44$ at constant $\phi=0.10$ raises $a_{S S I}$ by only $9 \mathrm{~s}^{-1}$. On the other hand, Fig. $8 \mathrm{~b}$ shows that SSI is quite sensitive to the equivalence ratio, as a rise from $\phi=0.08$ to $\phi=0.11$ at constant $X_{F}=0.35$ results in a $31 \mathrm{~s}^{-1}$ increase in $a_{S S I}$. Two important questions follow from this point. First, what is controlling SSI that is so strongly influenced by the premixed portion of the flame? Second, where in the flame does ignition actually occur?

A rate coefficient sensitivity analysis, shown in Fig. 9, reveals the most important reactions affecting $a_{S S I}$ in a DME partially premixed cool flame. The sensitivities at three different flame temperatures are shown: $T_{\max }=963 \mathrm{~K}$ (firmly on the stable cool flame branch), $T_{\max }=992 \mathrm{~K}$ (directly before the SSI limit), and $T_{\max }=1015 \mathrm{~K}$ (located on the unstable branch). As the temperature increases, SSI becomes most sensitive to the hydrogen peroxide decomposition reaction, $\mathrm{H}_{2} \mathrm{O}_{2}(+\mathrm{M})=\mathrm{OH}+\mathrm{OH}$ 
$(+\mathrm{M})$, as is typical for a second-stage ignition process at intermediate temperatures $[2,21,37]$. This reaction completes the conversion of $\mathrm{HO}_{2}$, a relatively inactive radical at lower temperatures, into the active radical $\mathrm{OH}\left(\mathrm{HO}_{2}\right.$ combines to form $\mathrm{H}_{2} \mathrm{O}_{2}$ through $\left.\mathrm{HO}_{2}+\mathrm{HO}_{2}=\mathrm{H}_{2} \mathrm{O}_{2}+\mathrm{O}_{2}\right)$. Also important is the competition between products of the $\mathrm{CH}_{3}+\mathrm{HO}_{2}$ reaction. The creation of the active radicals $\mathrm{CH}_{3} \mathrm{O}+\mathrm{OH}$ stimulates SSI, while $\mathrm{CH}_{3}+\mathrm{HO}_{2}=\mathrm{CH}_{4}+\mathrm{O}_{2}$ is a chain-terminating reaction which suppresses SSI. Although somewhat counterintuitive, the low-temperature reactions $\mathrm{CH}_{3} \mathrm{OCH}_{2} \mathrm{O}_{2}=\mathrm{CH}_{2} \mathrm{OCH}_{2} \mathrm{O}_{2} \mathrm{H}$ and $\mathrm{CH}_{2} \mathrm{OCH}_{2} \mathrm{O}_{2} \mathrm{H}+\mathrm{O}_{2}=\mathrm{O}_{2} \mathrm{CH}_{2} \mathrm{OCH}_{2} \mathrm{O}_{2} \mathrm{H}$ actually promote SSI, whereas the fuel radical decomposition reaction $\mathrm{CH}_{2} \mathrm{OCH}_{2}=\mathrm{CH}_{2} \mathrm{O}+\mathrm{CH}_{3}$ and QOOH decomposition reaction $\mathrm{CH}_{2} \mathrm{OCH}_{2} \mathrm{O}_{2} \mathrm{H}=\mathrm{OH}+2 \mathrm{CH}_{2} \mathrm{O}$ more common to high-temperature chemistry are inhibitive. This is due to the fact that the lowtemperature reactions are part of a chain-branching sequence that results in two $\mathrm{OH}$ radicals and another oxygenated radical, but the decomposition reactions produce only a single radical species $[26,38]$.

For a partially premixed flame with two separate reaction zones, it is not only important how radicals are produced but also where they form. For a cool flame at the same conditions as the one in Fig. $6\left(X_{F}=0.35, \phi=0.08, a=73 \mathrm{~s}^{-1}\right)$, a path flux analysis reveals that $83 \%$ of the $\mathrm{HO}_{2}$ radical formation takes place on the premixed flame side of the double flame, mostly $(69 \%)$ through $\mathrm{HCO}+\mathrm{O}_{2}=\mathrm{CO}+\mathrm{HO}_{2}$. Because $\mathrm{H}_{2} \mathrm{O}_{2}$ is predominately ( $82 \%$ ) formed from the $\mathrm{HO}_{2}+\mathrm{HO}_{2}$ combination reaction, $75 \%$ of $\mathrm{H}_{2} \mathrm{O}_{2}$ also forms on the premixed side. As the equivalence ratio increases, so does the rate of the $\mathrm{HCO}+\mathrm{O}_{2}$ reaction, the production of $\mathrm{HO}_{2}$, and the production of $\mathrm{H}_{2} \mathrm{O}_{2}$. Fig 10 shows the sensitivity of the $\mathrm{H}_{2} \mathrm{O}_{2}$ net production to the equivalence ratio as the conditions for SSI are approached. A small increase from $\phi=$ 0.090 to $\phi=0.107$ at $X_{F}=0.35$ is enough to cause a $45 \%$ gain in the peak $\mathrm{H}_{2} \mathrm{O}_{2}$ production. Fuel loading (not pictured), on the other hand, is much less impactful. An increase from $X_{F}=0.25$ to $X_{F}=0.44$ leads to only a $2 \%$ rise in the peak $\mathrm{H}_{2} \mathrm{O}_{2}$ production. 
$\mathrm{H}_{2} \mathrm{O}_{2}$ production is, of course, important for SSI; however, it is not the production of $\mathrm{H}_{2} \mathrm{O}_{2}$ that ultimately leads to ignition but its decomposition through $\mathrm{H}_{2} \mathrm{O}_{2}=\mathrm{OH}+\mathrm{OH}$. Moreover, while $\mathrm{H}_{2} \mathrm{O}_{2}$ is primarily produced inside the premixed flame, the $\mathrm{H}_{2} \mathrm{O}_{2}=\mathrm{OH}+\mathrm{OH}$ reaction is favored closer to the diffusion side, as seen in Fig. 10. This reaction accounts for $25 \%$ of the total $\mathrm{H}_{2} \mathrm{O}_{2}$ consumption on the diffusion side but a mere $8 \%$ on the premixed side.

Therefore, the mechanism for second-stage ignition in a partially premixed cool flame is as follows: $\mathrm{HO}_{2}$ is produced in the premixed cool flame, where it quickly reacts with itself to form $\mathrm{H}_{2} \mathrm{O}_{2}$. However, $\mathrm{H}_{2} \mathrm{O}_{2}$ decomposition into $\mathrm{OH}$ does not occur immediately. Instead, $\mathrm{H}_{2} \mathrm{O}_{2}$ diffuses out of the premixed flame reaction zone and towards the diffusion flame. Approaching the diffusion flame, $\mathrm{H}_{2} \mathrm{O}_{2}$ decomposition accelerates and ignition occurs. This phenomenon can be seen in the images from a highspeed video in Fig. 11 (the full video is available in the supplemental material). Beginning with a stable partially premixed cool flame at $X_{F}=0.44, \phi=0.11$, and $a=73 \mathrm{~s}^{-1}$, the fuel loading is gradually increased up to the SSI limit, which occurs near $X_{F}=0.48$. The chemiluminescence from the premixed cool flame can be seen $8 \mathrm{~ms}$ before ignition. Though the frame rate $(125 \mathrm{fps})$ has been slowed in order to visualize the premixed flame, the cool diffusion flame is still too dim to be captured. At SSI $(t=0)$, an ignition kernel appears between the upper burner and the premixed flame in the vicinity of the diffusion flame front. The kernel then quickly expands to fill the entire region between the two burners by $t=8 \mathrm{~ms}$. 296 ms after ignition, the flame has stabilized into a double hot flame. In the testing of SSI caused by either fuel loading increases or equivalence ratio increases, the ignition kernel consistently appeared on the diffusion flame side of the burner, usually about halfway between the upper burner and the premixed flame.

\section{Conclusion}


Self-sustaining partially premixed cool flames have been successfully established and examined in a counterflow burner with ozone sensitization. Three different methods for cool flame formation-autoignition, laser-induced ignition, and extinction transition from a hot flame - are presented. It is observed that at low fuel concentrations a cool flame can exist beyond the flammability limit of a hot flame. The establishment of double cool flames with distinct diffusion cool flame and premixed cool flame sides is shown to be possible at increased fuel loading and equivalence ratios. It is seen that numerical calculations can reproduce the double cool flame structure at moderate fuel loading and low equivalence ratios but struggle to predict the second-stage ignition limit. An investigation of second-stage ignition reveals that equivalence ratio increases on the premixed side affect the second-stage ignition strain rate much more than increased fuel loading on the diffusion side. Detailed kinetic modeling and experimental results show that increases in the equivalence ratio cause heightened $\mathrm{HO}_{2}$ and $\mathrm{H}_{2} \mathrm{O}_{2}$ production in the premixed cool flame; however, the $\mathrm{H}_{2} \mathrm{O}_{2}$ decomposition reaction most responsible for second-stage ignition does not occur until the hydrogen peroxide has diffused toward the diffusion flame.

\section{Acknowledgement}

The authors recognize the support of NSF grant CBET-1507358, NASA ISS Post-Graduate award NNX15AB67G, and the DoD NDSEG Fellowship program. 


\section{Figure Captions}

Fig. 1. Schematic of the experiment's ozone-assisted counterflow burner in the partially premixed flame configuration.

Fig. 2. Plots of (a) maximum flame intensity and (b) the location of the maximum flame intensity versus time in the transition from a hot premixed flame to a cool premixed flame at $a=59 \mathrm{~s}^{-1}$ (momentum imbalanced) and $3.5 \% \mathrm{O}_{3}$, during which the equivalence ratio is gradually decreased from $\phi=0.102$ to $\phi$ $\approx 0.09$.

Fig. 3. Direct photographs of (a) a double cool flame and (b) a double hot flame, both at $X_{F}=0.44, \phi=$ $0.11, a=73 \mathrm{~s}^{-1}$, and $3.5 \% \mathrm{O}_{3}$ in the oxidizer. The shutter speeds are 1 second and $1 / 100$ second, respectively, and the cool flame image is enhanced in brightness by a factor of 5 . A scale for the burner distance is included.

Fig. 4. Raw $\mathrm{CH}_{2} \mathrm{O}$ PLIF images of (a) a double cool flame and (b) a double hot flame, both at $X_{F}=0.44$, $\phi=0.11$, and $a=73 \mathrm{~s}^{-1}$. The dashed lines indicate the approximate locations of the stagnation planes.

Fig. 5. (a) Calculated double hot flame temperature and heat release rate and (b) centerline $\mathrm{CH}_{2} \mathrm{O}$ PLIF signals of double cool and hot flames at $X_{F}=0.44, \phi=0.11$, and $a=73 \mathrm{~s}^{-1}$, with the calculated $\mathrm{CH}_{2} \mathrm{O}$ mole fraction for the hot flame included for comparison. The distance is measured from the upper burner exit.

Fig. 6. (a) Calculated temperature and heat release rate and (b) comparison between the centerline $\mathrm{CH}_{2} \mathrm{O}$ PLIF signal and the calculated $\mathrm{CH}_{2} \mathrm{O}$ mole fraction for a partially premixed cool flame at $X_{F}=0.35, \phi=$ 0.08 , and $a=73 \mathrm{~s}^{-1}$.

Fig. 7. Regime diagram for partially premixed DME/ $\mathrm{N}_{2}$ versus $\mathrm{DME} / \mathrm{O}_{2} / \mathrm{O}_{3}$ cool flames at $a=73 \mathrm{~s}^{-1}$ with both experimental and numerical modeling results included. Above the SSI limit, cool flames are unstable.

Fig. 8. S-curve comparisons of the impact of (a) fuel loading and (b) equivalence ratio increases on the second-stage ignition strain rate, $a_{S S I}$. The $X_{F}=0.35$ and $\phi=0.10$ condition is included in both cases.

Fig. 9. Rate constant sensitivity analysis for the second-stage ignition strain rate, $a_{S S I}$, of a partially premixed cool flame at $X_{F}=0.35, \phi=0.10$, and three different flame temperatures near SSI.

Fig. 10. Spatial profiles of $\mathrm{H}_{2} \mathrm{O}_{2}$ net production and $\mathrm{H}_{2} \mathrm{O}_{2}=\mathrm{OH}+\mathrm{OH}$ for a partially premixed cool flame at $X_{F}=0.35$ and three different equivalence ratios. 
Fig. 11. Direct images from a high-speed camera $(125 \mathrm{fps})$ showing second-stage ignition in a partially premixed cool flame at $\phi=0.11, a=73 \mathrm{~s}^{-1}, 3.5 \% \mathrm{O}_{3}$, and a fuel loading of approximately $X_{F}=0.48$. Time $t=0$ is set to the first appearance of the ignition kernel. 


\section{References}

[1] P.R. Ballinger, P.R. Ryason, Proc. Combust. Inst. 13 (1971) 271-277.

[2] H. Yamada, K. Suzaki, A. Tezaki, Y. Goto, Combust. Flame 154 (2008) 248-258.

[3] V. Nayagam, D.L. Dietrich, P.V. Ferkul, M.C. Hicks, F.A. Williams, Combust. Flame 159 (2012) 3583-3588.

[4] H. Davy, Phil. T. Roy. Soc. 107 (1817) 77-83.

[5] W.H. Perkin, J. Chem. Soc. 41 (1882) 363-367.

[6] P.G. Lignola, E. Reverchon, Prog. Energy Combust. Sci. 13 (1987) 75-96.

[7] J.F. Griffiths, T. Inomata, J. Chem. Soc. Faraday Trans. 88 (1992) 3153-3158.

[8] L.R. Cairnie, A.J. Harrison, P.A. Morgan, Proc. Combust. Inst. 18 (1981) 1799-1806.

[9] H. Oshibe, H. Nakamura, T. Tezuka, S. Hasegawa, K. Maruta, Combust. Flame 157 (2010) 15721580.

[10] S. Kikui, T. Kamada, H. Nakamura, T. Tezuka, S. Hasegawa, K. Maruta, Proc. Combust. Inst. 35 (2015) 3405-3412.

[11] M. Foster, H. Pearlman, Combust. Flame 147 (2006) 108-117.

[12] V. Nayagam, D.L. Dietrich, M.C. Hicks, F.A. Williams, Combust. Flame 162 (2015) 2140-2147.

[13] W. Sun, S.H. Won, T. Ombrello, C. Carter, Y. Ju, Proc. Combust. Inst. 34 (2013) 847-855.

[14] S.H. Won, B. Jiang, P. Diévart, C.H. Sohn, Y. Ju, Proc. Combust. Inst. 35 (2015) 881-888.

[15] C.B. Reuter, S.H. Won, Y. Ju, Combust. Flame 166 (2016) 125-132.

[16] S.K. Aggarwal, Prog. Energy Combust. Sci. 35 (2009) 528-570.

[17] A. Krisman, E.R. Hawkes, M. Talei, A. Bhagatwala, J.H. Chen, Proc. Combust. Inst. 35 (2015) 999-1006.

[18] S. Deng, P. Zhao, M.E. Mueller, C.K. Law, Combust. Flame 162 (2015) 4471-4478.

[19] S. Saxena, I.D. Bedoya, Prog. Energy Combust. Sci. 39 (2013) 457-488.

[20] S.L. Kokjohn, R.M. Hanson, D.A. Splitter, R.D. Reitz, Int. J. Engine Res. 12 (2011) 209-226.

[21] C.K. Westbrook, Proc. Combust. Inst. 28 (2000) 1563-1577.

[22] S.H. Won, W. Sun, Y. Ju, Combust. Flame 157 (2010) 411-420.

[23] S.H. Won, S. Dooley, F.L. Dryer, Y. Ju, Proc. Combust. Inst. 33 (2011) 1163-1170.

[24] S.H. Won, S. Dooley, F.L. Dryer, Y. Ju, Combust. Flame 159 (2012) 541-551.

[25] J.K. Lefkowitz, S.H. Won, Y. Fenard, Y. Ju, Proc. Combust. Inst. 34 (2013) 813-820.

[26] Z. Zhao, M. Chaos, A. Kazakov, F.L. Dryer, Int. J. Chem. Kinet. 40 (2008) 1-18.

[27] W.K. Metcalfe, S.M. Burke, S.S. Ahmed, H.J. Curran, Int. J. Chem. Kinet. 45 (2013) 638-675.

[28] J.C. Prince, F.A. Williams, Combust. Flame 162 (2015) 3589-3595.

[29] T. Ombrello, S.H. Won, Y. Ju, S. Williams, Combust. Flame 157 (2010) 1906-1915.

[30] U. Niemann, K. Seshadri, F.A. Williams, Combust. Flame 162 (2015) 1540-1549.

[31] J.E. Harrington, K.C. Smyth, Chem. Phys. Lett. 202 (1993) 196-202.

[32] Y. Ju, W. Sun, Prog. Energy Combust. Sci. 48 (2015) 21-83.

[33] A.E. Lutz, R.J. Kee, J.F. Grcar, F.M. Rupley, OPPDIF: A Fortran program for computing opposedflow diffusion flames Sandia National Laboratories Report 96-8243 (1997).

[34] R.J. Kee, J.F. Grcar, M.D. Smooke, J.A. Miller, E. Meeks, "PREMIX: A Fortran program for modeling steady laminar one-dimensional premixed flames," Sandia National Laboratories Report 858240, (1985).

[35] Y. Ju, H. Guo, K. Maruta, F. Liu, J. Fluid Mech. 342 (1997) 315-334. 
[36] Y. Ju, C.B. Reuter, S.H. Won, Combust. Flame 162 (2015) 3580-3588.

[37] F.L. Dryer, Proc. Combust. Inst. 35 (2015) 117-144.

[38] J. Zádor, C.A. Taatjes, R.X. Fernandes, Prog. Energy Combust. Sci. 37 (2011) 371-421. 


\section{List of Supplemental Material}

Fig. S1. High-speed video (125 fps) of the transition from a premixed hot flame to a premixed cool flame at $a=59 \mathrm{~s}^{-1}$ (momentum imbalanced) and $3.5 \% \mathrm{O}_{3}$, during which the equivalence ratio is gradually decreased from $\phi=0.102$ to $\phi=0.09$.

Fig. S2. High-speed video (125 fps) showing second-stage ignition in a partially premixed cool flame at $\phi=0.11, a=73 \mathrm{~s}^{-1}, 3.5 \% \mathrm{O}_{3}$, and a fuel loading of approximately $X_{F}=0.48$. 
Figure 1

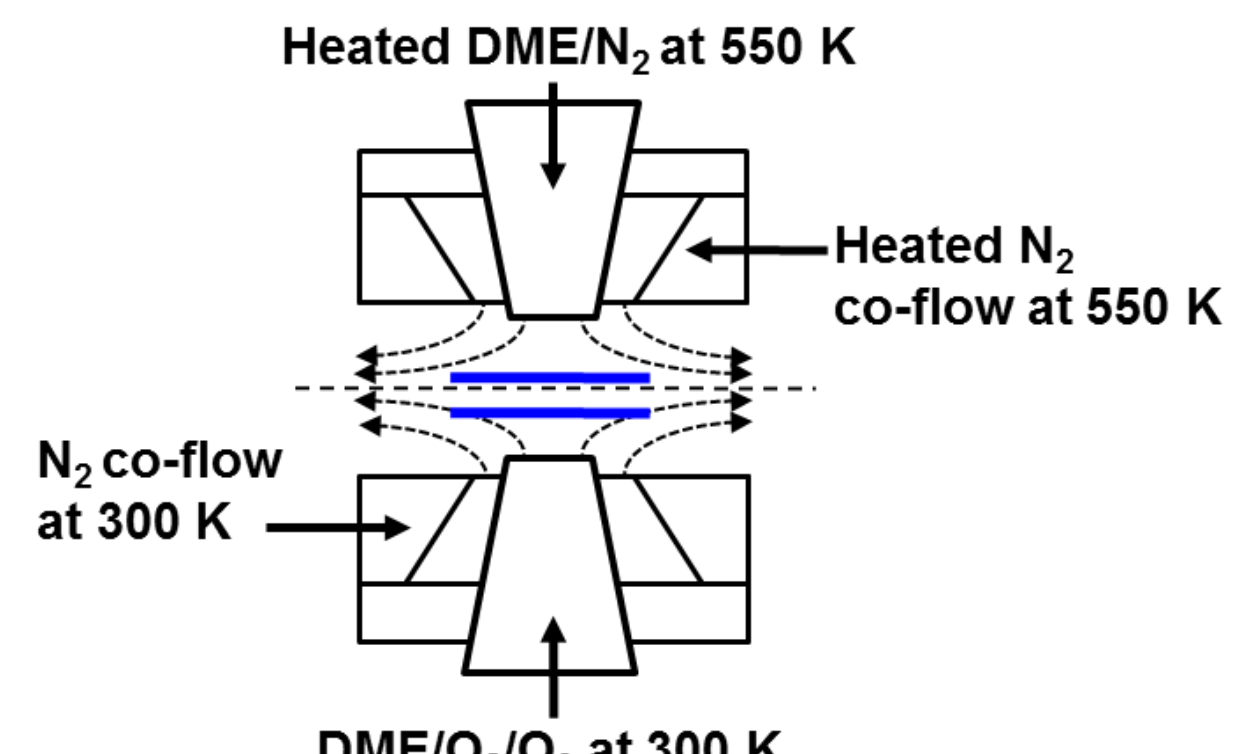
$\mathrm{DME} / \mathrm{O}_{2} / \mathrm{O}_{3}$ at $300 \mathrm{~K}$

Heated DME/ $\mathrm{N}_{2}$ at $550 \mathrm{~K}$ co-flow at $550 \mathrm{~K}$

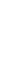

$\mathrm{N}_{2}$ co-flow at $300 \mathrm{~K}$

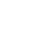




\section{Figure 2}
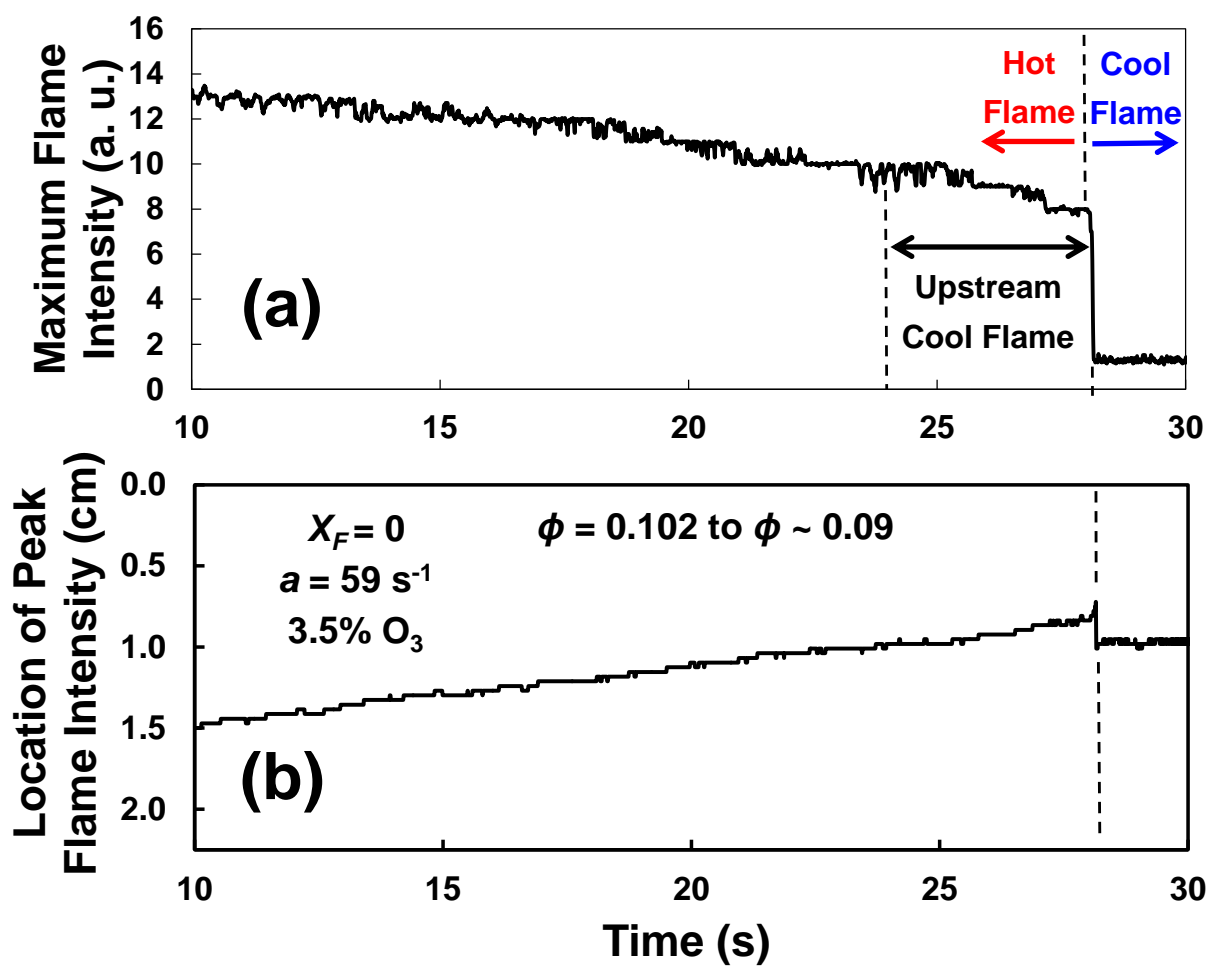
Figure 3

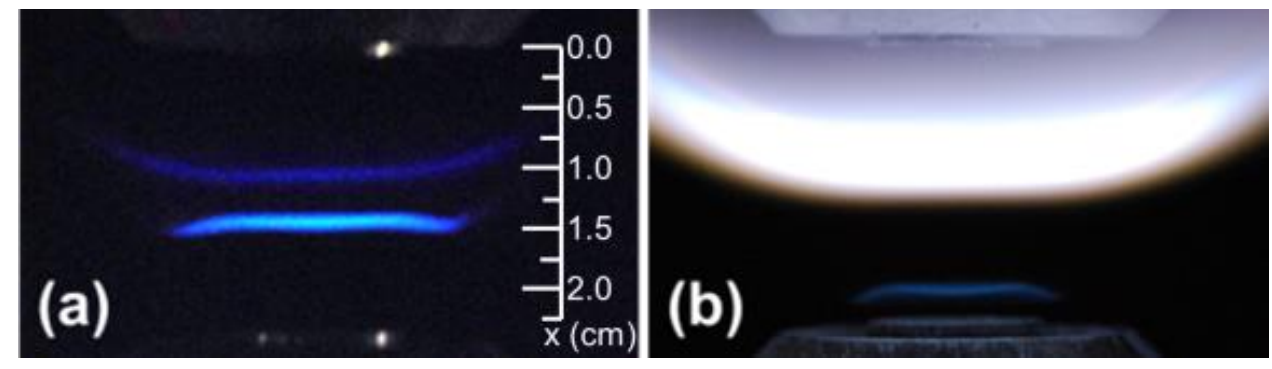


Figure 4
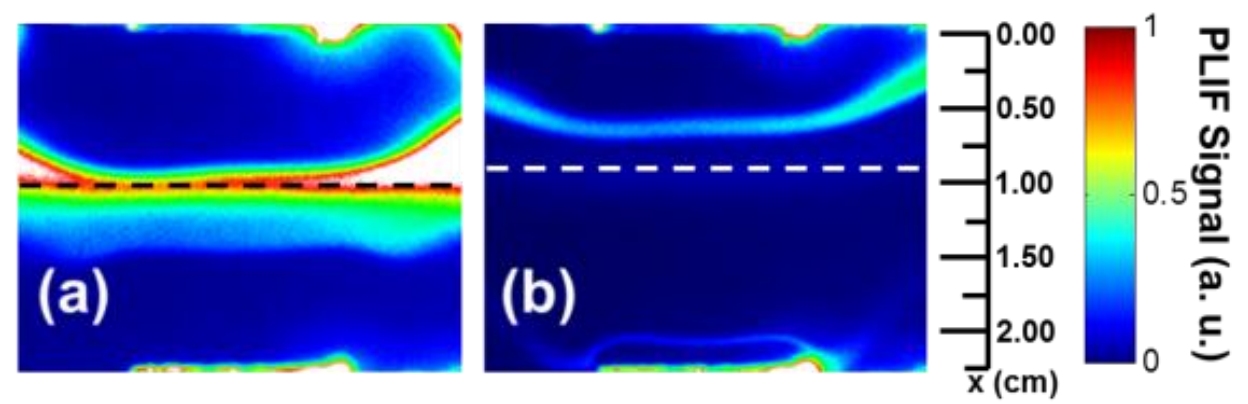


\section{Figure 5}
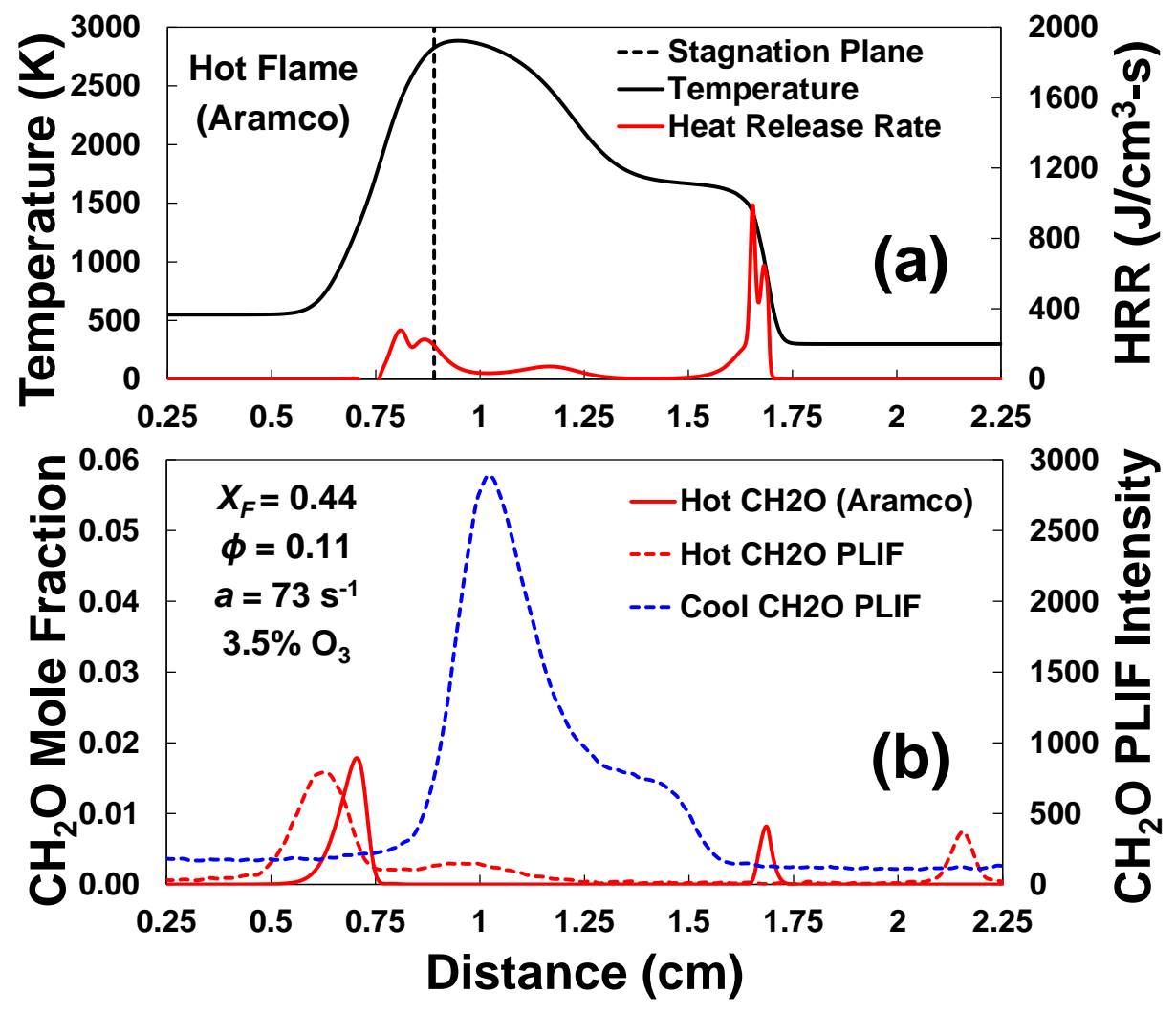
Figure 6

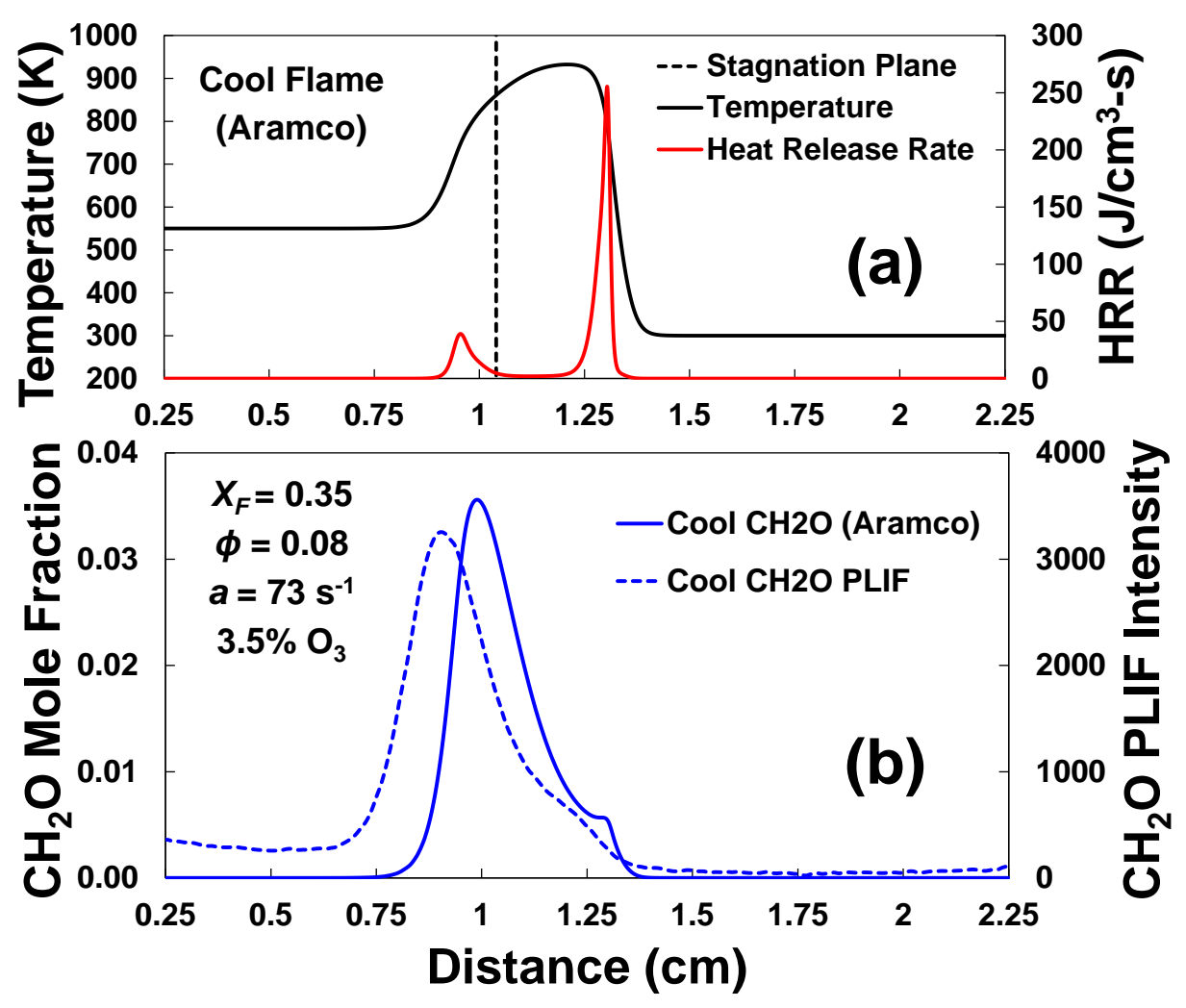




\section{Figure 7}

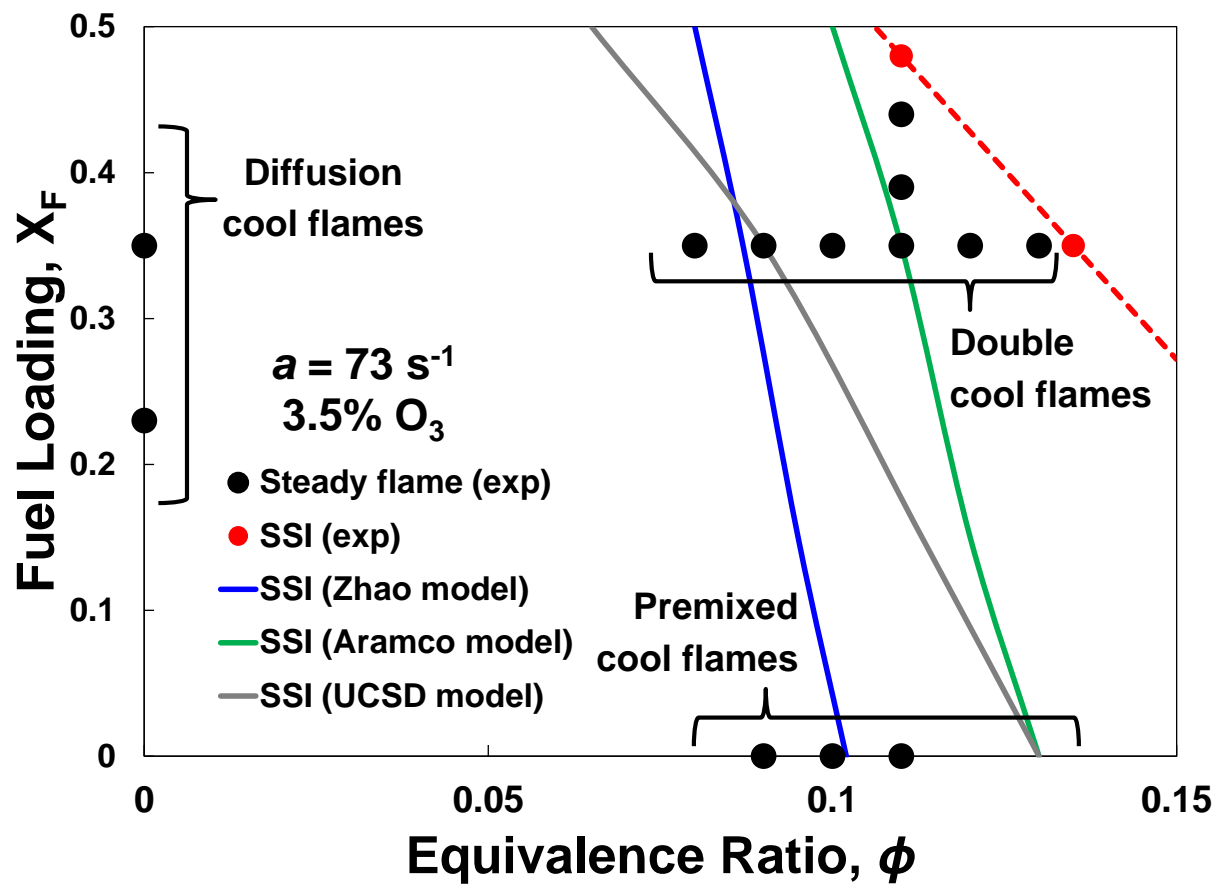


Figure 8

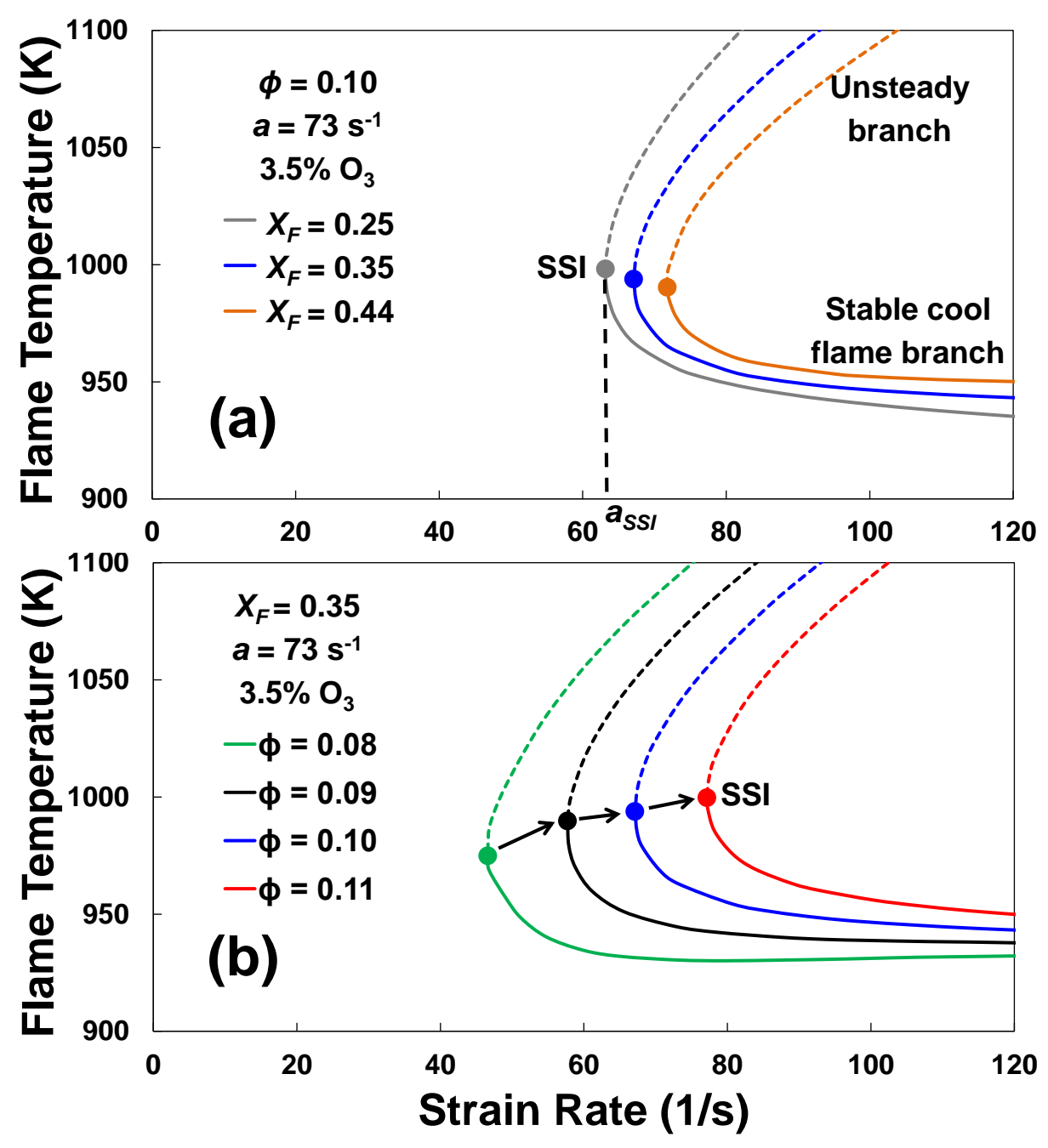




\section{Figure 9}

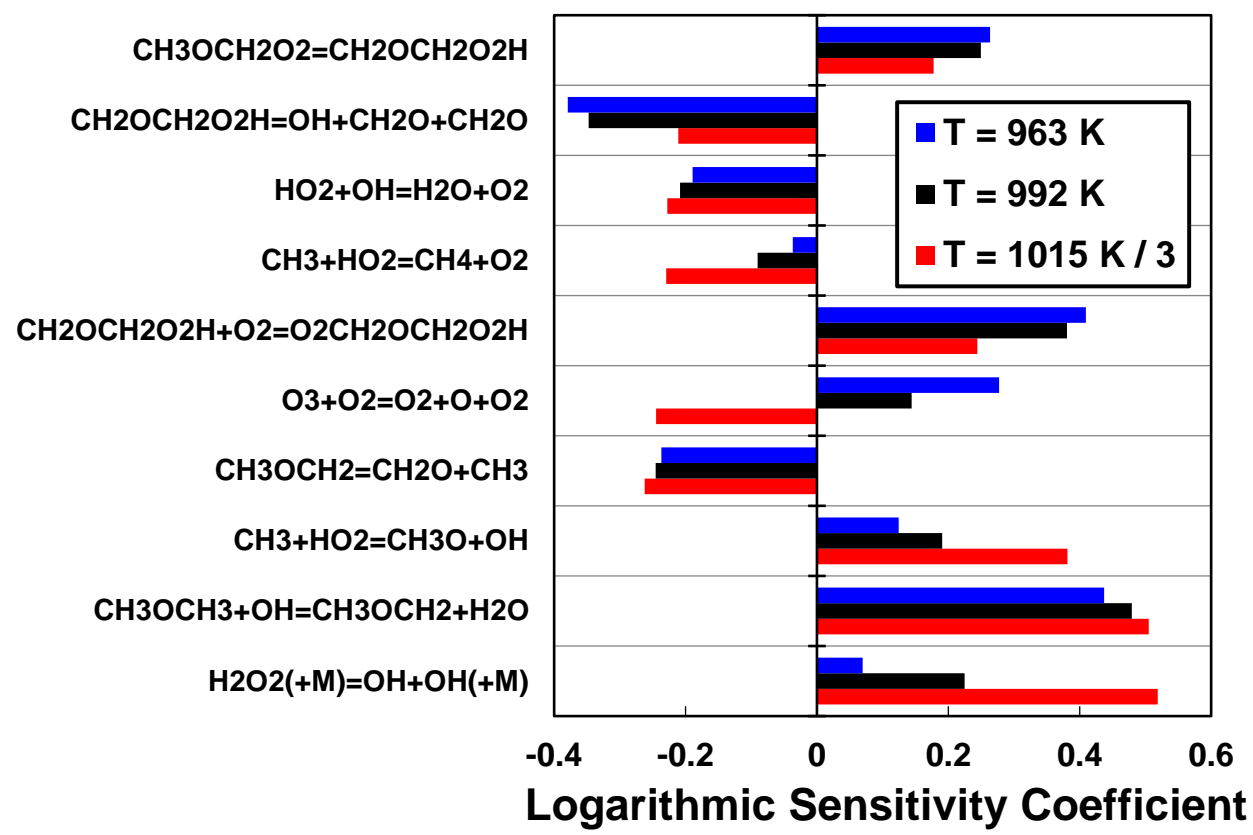




\section{Figure 10}

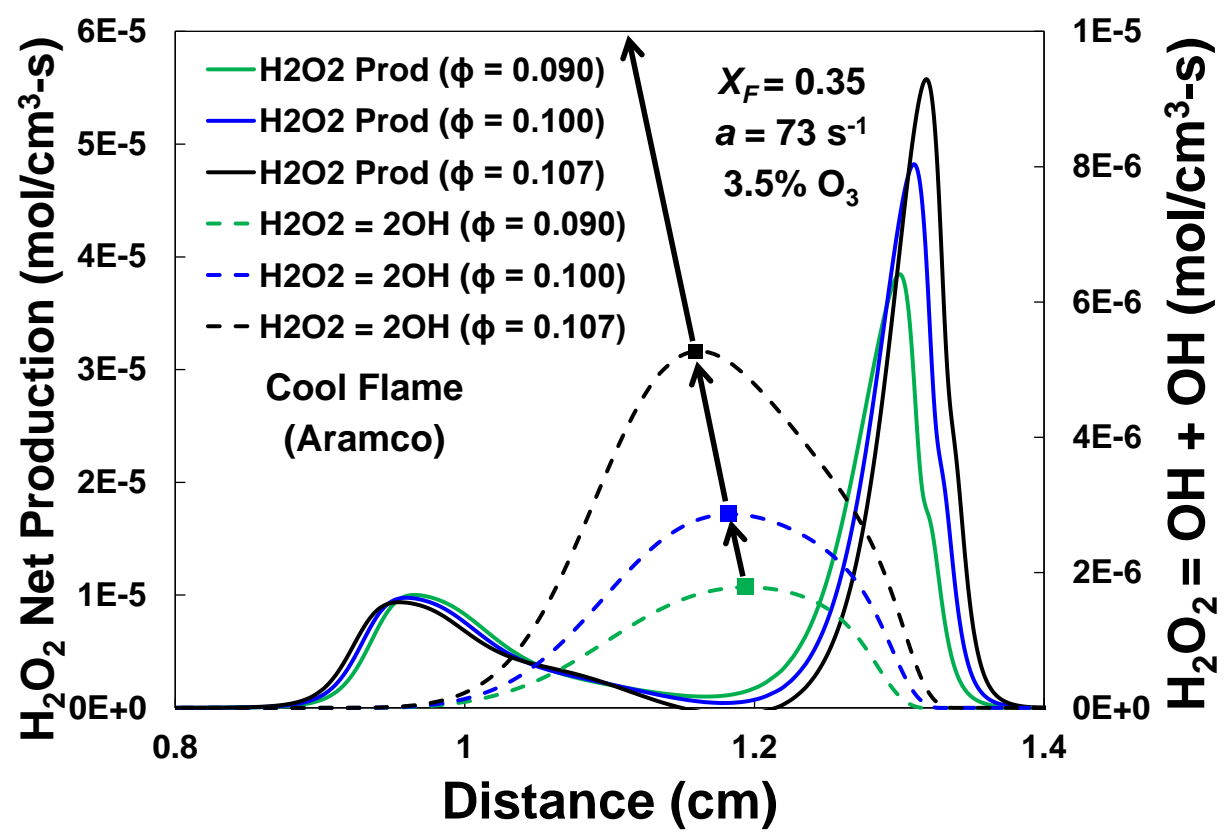




$$
\text { Figure } 11
$$
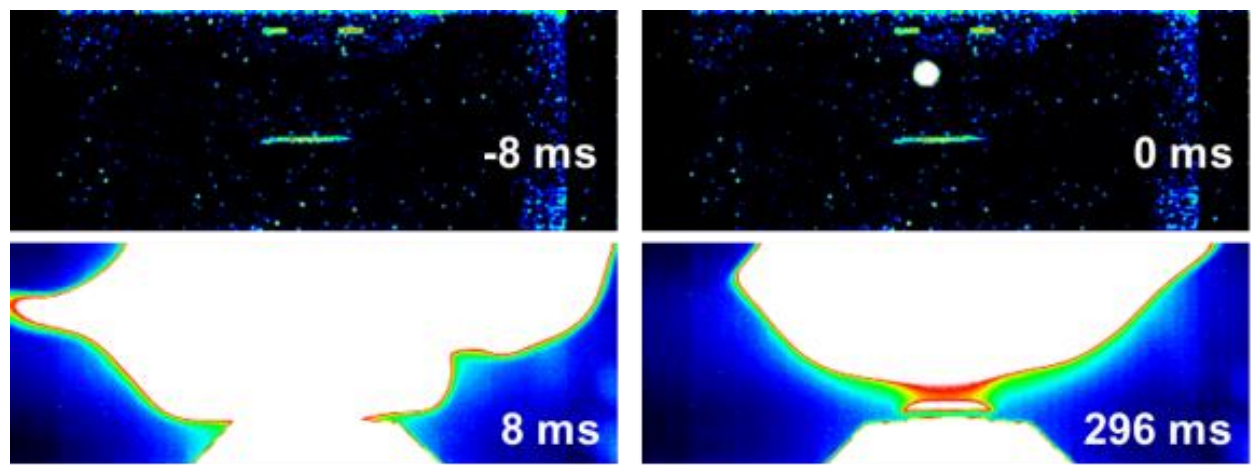